\title{
VERIFICATION OF PLUNGER COOLING FOR GLASS FORMING IN REAL WORKING MODE
}

\author{
Michal STARÝ, Petr SALAČ•

\begin{abstract}
The article presents results of experimental verification of plunger watercooling for glass forming in a working cycle which has been set by a real working mode. Results have been submitted in the form of confrontation of the temperature distributions across classical and optimized plunger surfaces. During the experiment, the glass was replaced by a tin bath.
\end{abstract}

\section{INTRODUCTION}

The hot forming of vases and similar glass products involves a wide variety of technological requirements [5]. Two main problems appear during glass forming on the surface of a moulded product. If the surface of the plunger is too hot at the moment of separation, then the glass melt adheres to the device and deformation of the moulded piece follows. Conversely, if the surface of the plunger is too cold, then small fire cracks appear on the surface of the moulded piece. Therefore it is desirable to reach a constant distribution of temperature across the surface of the plunger at the moment of separation.

For the purpose of optimization a simulation of the process in the software Fluent [3] was realized. Then a special laboratory workplace for numerical results verification was built [6]. Experimental results of optimization by comparison between the classical plunger (a drilled hole and a common pipe inlet) and the optimized plunger (a shape-optimized cavity and a flow control body inlet) was documented. The first stage of the experiment as a static case (permanently plunged plunger) was realized $[4,6]$. Submitted article deals with a second stage of the experiment where the plunger works in a cyclic movement as in a real working mode.

\section{EXPERIMENTAL WORKPLACE DESCRIPTION}

Photos of the workplace are presented in figure 1 where a view of the complete workplace with plunger and cuts of classical and optimized plunger with marked position of the thermocouples are shown. The main part of created laboratory workplace is a special pot-type furnace. A cast-iron melting pot with melted tin inside (the substitute for the glass melt) is put into the furnace cavity $[1,2,7]$. The plunger established in two parallel pneumatic cylinders is plunged into the tin bath. Both plunger versions are equipped with 12 sheathed thermocouples (K-type) which are distributed across the surface at different places (see figure 1 ) and at relevant depths (see table 1) of the plungers in order to monitor the temperature field.

\footnotetext{
- Ing. Michal Starý, Ph.D., Technical University of Liberec, Department of Glass Producing Machines and Robotics, Studentská 2, Liberec 1, 461 17, michal.stary@tul.cz

RNDr. Petr Salač, CSc., Technical University of Liberec, Department of Mathematics and Didactics of Mathematics, Studentská 2, Liberec 1, 461 17, petr.salac@tul.cz
}

This is an Open Access article distributed under the terms of the Creative Commons Attribution License 2.0, which permits unrestricted use, distribution, and reproduction in any medium, provided the original work is properly cited. 


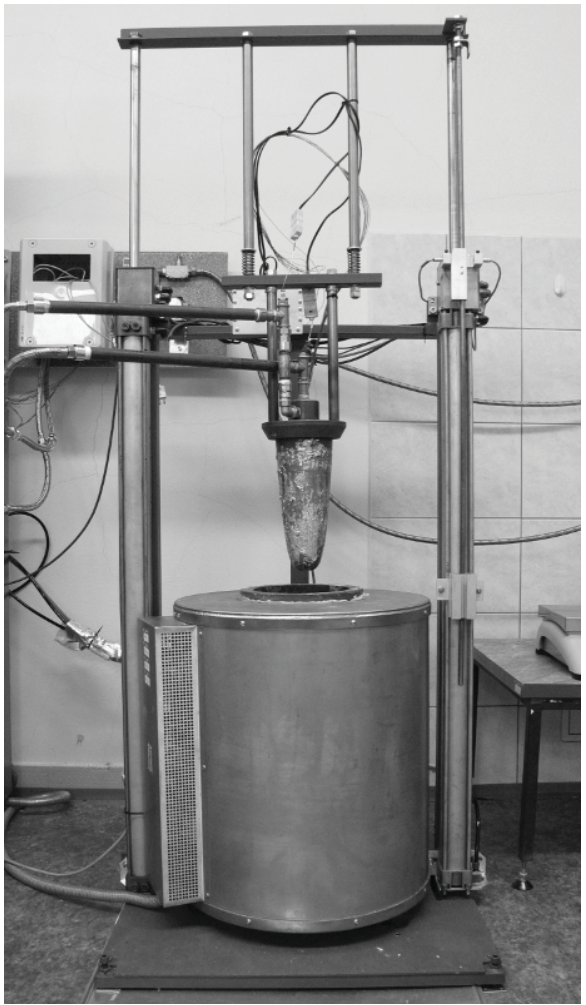

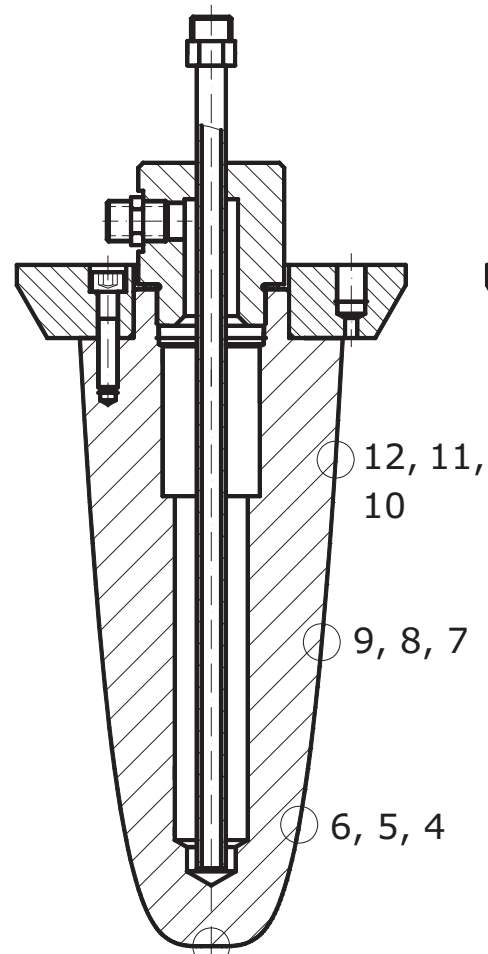

$3,2,1$

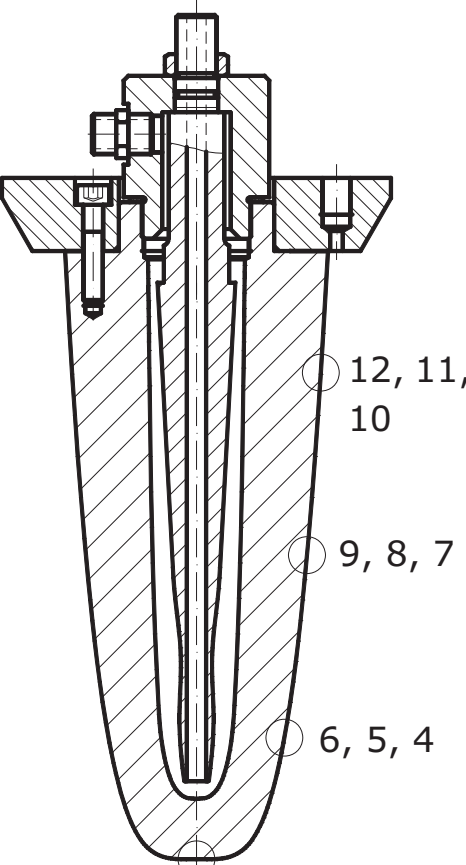

$3,2,1$

Figure 1: Laboratory workplace and cuts of classical and optimized plunger

\begin{tabular}{|l|c|c|c|c|c|c|c|c|c|c|c|c|}
\hline Number of thermocouple & 1 & 2 & 3 & 4 & 5 & 6 & 7 & 8 & 9 & 10 & 11 & 12 \\
\hline Distance from surface $[\mathrm{mm}]$ & 5 & 10 & 15 & 5 & 10 & 15 & 5 & 15 & 25 & 5 & 15 & 25 \\
\hline
\end{tabular}

Table 1: Distance of thermocouples in the plunger from its surface

\section{EXPERIMENT DESCRIPTION}

The preparatory work consists of the tin melting where the furnace temperature is set to $600{ }^{\circ} \mathrm{C}$, the plunger preheating to $50-70^{\circ} \mathrm{C}$ and of the water cooling activation where the flow is set to $1 \mathrm{l} / \mathrm{min}$. The flow is set with respect to water boil prevention.

The experiment starts with the plunger movement initialisation, or more precisely plunging the plunger into the tin bath. The plunger working cycle takes $28 \mathrm{~s}$ and is shown in figure 2. Monitored temperature course is automatically recorded with a frequency of $10 \mathrm{~Hz}$ except the tin bath temperature which is measured occasionally by hand.

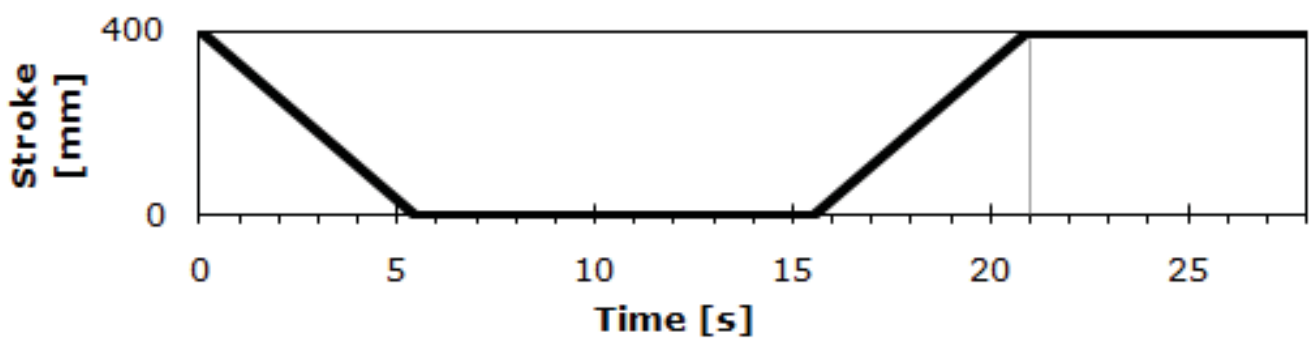

Figure 2: Working mode of the plungers 
4. Results Overview
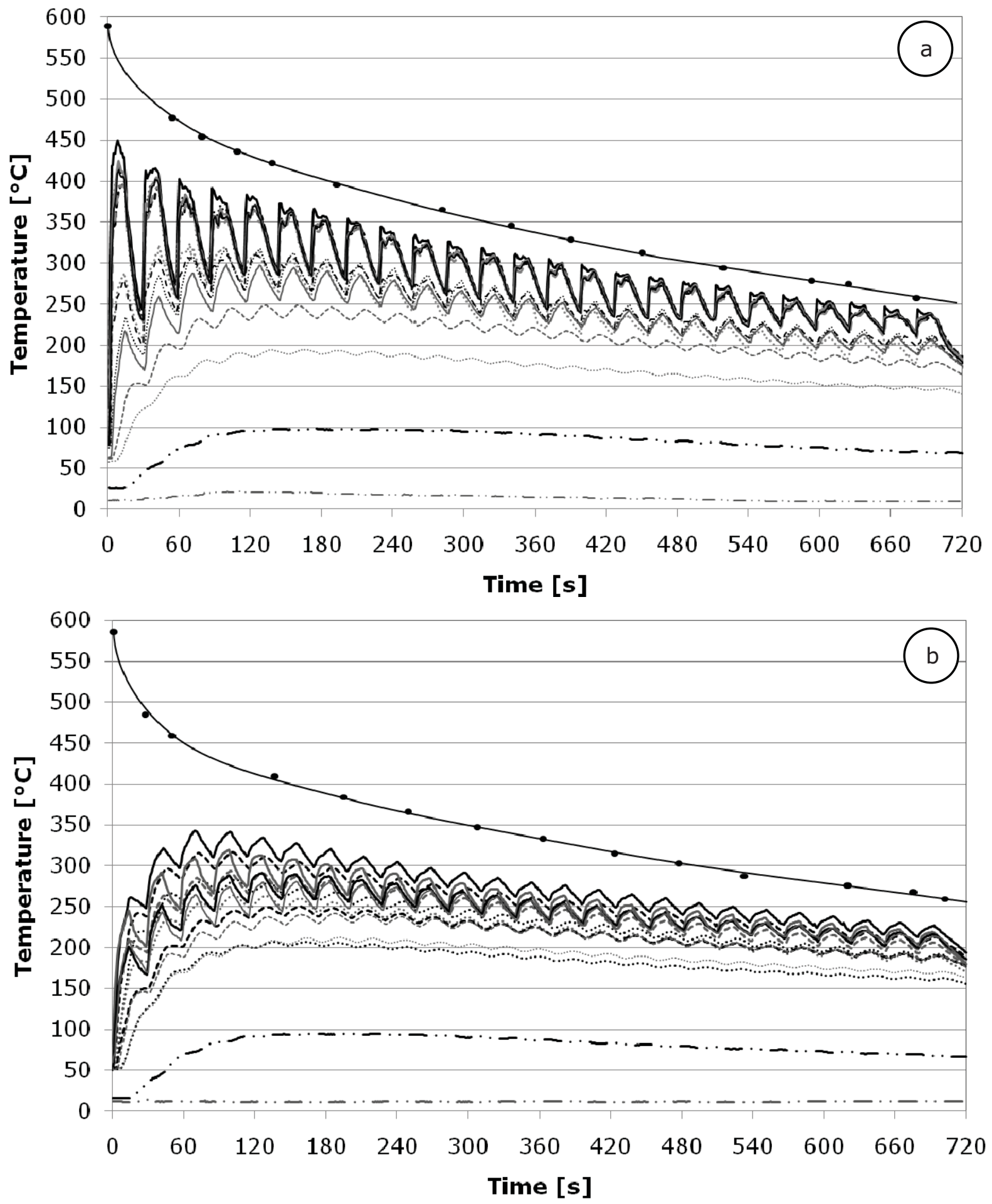

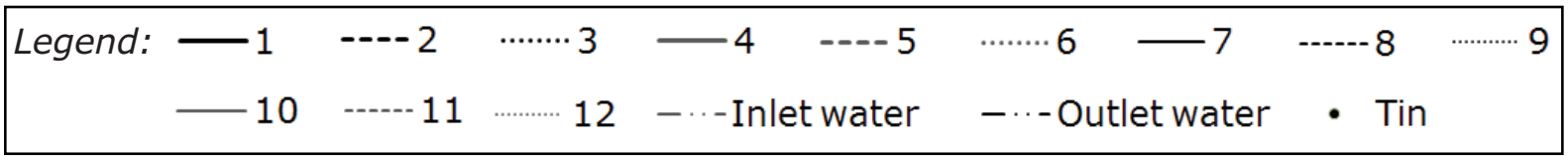

Figure 3: Time course of all measured temperatures of plunger I and II

a) Plunger I: classical plunger with a drilled hole and a common cooling pipe

b) Plunger II: plunger with a shape-optimized cavity and a flow control body 

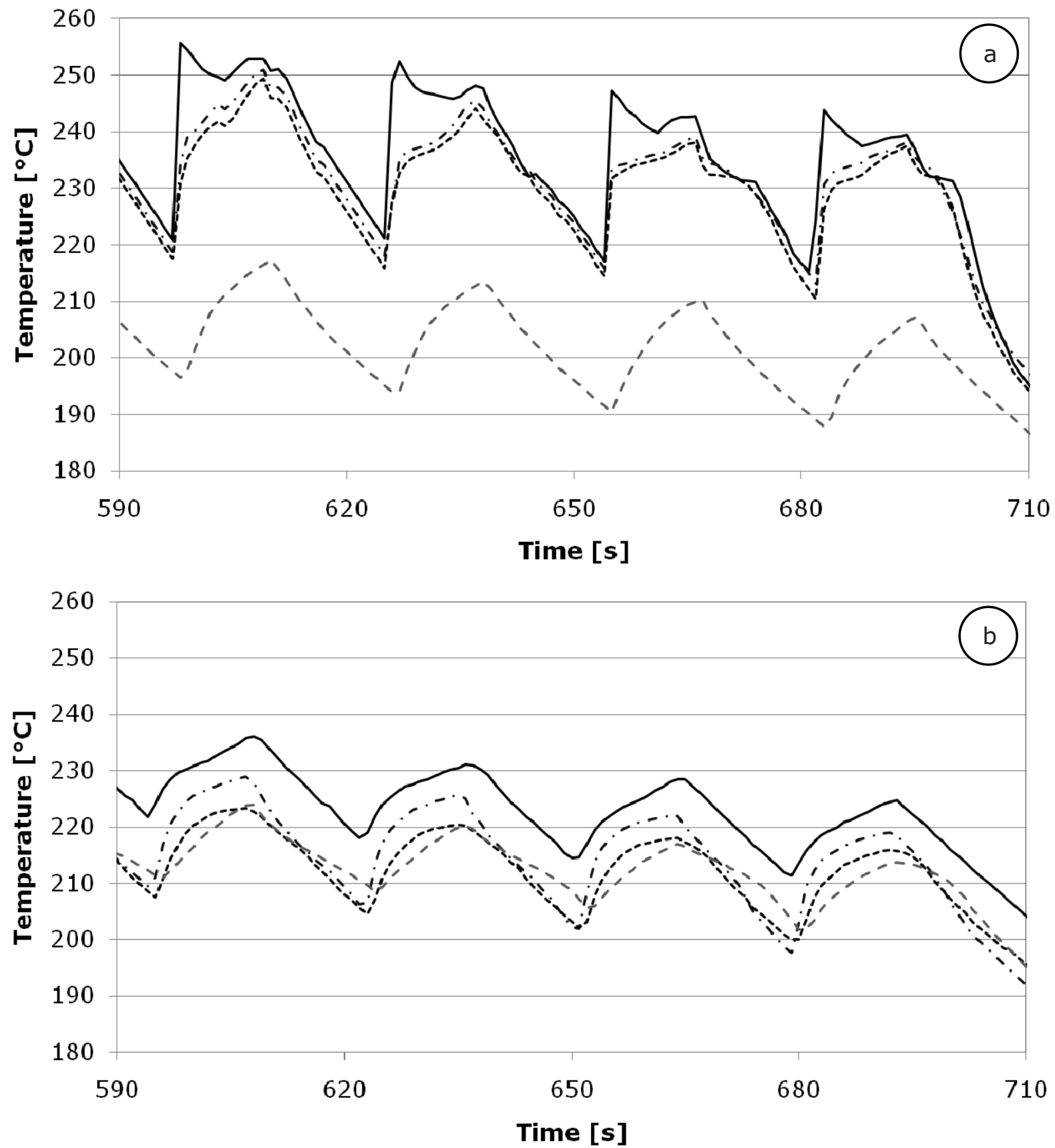

Legend: $-1 \quad-\cdot-4 \quad---7 \quad--\cdot 10$

Figure 4: Detail of time course of near-surface temperatures of plunger I and II

a) Plunger I: classical plunger with a drilled hole and a common cooling pipe

b) Plunger II: plunger with a shape-optimized cavity and a flow control body

Measured time course of all monitored mean temperatures for both plungers is shown in figure 3. Of course, it is necessary to consider the response time of the thermocouples. The temperature of the system during the process falls. The experiment duration is then limited by the tin freezing point $\left(232^{\circ} \mathrm{C}\right)$ when the tin begins to adhere to the surface of the plunger. Hence it was usually realized of the 25 working cycles. Described situation is given by the limited furnace power and especially by chosen experimental method, where 
still the same gob (bath) in contrast to the real working process is cooled. Hence a steady state of the working process which is the best for the evaluation wasn't reached. The pseudo-steady stage of the time course of the near-surface temperatures (thermocouples No. $1,4,7,10$ ) is in detail shown in figure 4 .

It is possible to claim that the uniform thickness of the optimized plunger body, without sharp passes of its shape which could leads to vortex flows, causes more uniform heat sink. Likewise, achieved lower temperature load may contributes to higher durability of the plunger. There is also possible to see that on the optimized plunger steadier (stepless and predictable) temperature course was reached. This fact can be helpful in the next stage of the numerical optimization where more specify boundary conditions and parameters will be used.

\section{Conclusion}

It is possible to claim that realized numerical optimization brought a significant improvement. On the optimized plunger, there was achieved more uniform heat sink and as about $50 \%$ lower temperature load of the plunger which can contributes to its higher durability. It also managed to eliminate the rapid temperature ups downs near the plunger surface. Because of common table parameters used in the current numerical optimization, it is reasonable to expect that with considering of more specify boundary conditions and parameters in the next stage of the research will be possible to obtain still better results.

\section{ACKNOWLEDgEMENT}

This paper was written with the support of the research project MSM 4674788501 financed by the Ministry of Education of the Czech Republic.

\section{REFERENCES}

[1] Bertram L. A., Zanner F. J.: Convective Simulation in Metal Solidification, Stability in Convective Flows, ASME, New York, 1986, pp. 99-107

[2] Fukusako S., Seki N.: Fundamental Aspects of Analytical and Numerical Methods on Freezing and Melting Heat Transfer Problems, Annual Review of Numerical Fluid Mechanics and Heat Transfer, 1987, vol. 1, pp. 351-402

[3] Salač P., Dvořák V.: Shape optimization of axially symmetric through cooling canal, $25^{\text {th }}$ conference with international participation Computational Mechanics 2009, Hrad Nečtiny, Czech Republic, 2009

[4] Salač P., Dvořák V.: Experimental verification of numerical optimization of a plunger for glass pressing, International conference, Experimental fluid mechanics 2010, Liberec, Czech Republic, 2010, pp. 582-586

[5] Smrček A.: Strojní tvarování skla, SNTL, Praha, 1981

[6] Starý M.: Physical modelling of plunger for glass forming, International conference, Experimental fluid mechanics 2010, Liberec, Czech Republic, 2010, pp. 629-635

[7] Viskanta R.: Heat Transfer During Melting and Solidification of Metals, Journal of Heat Transfer, ASME, 1988, vol. 110, iss. 4b, pp. 1205-1219 